January 2008

\title{
The Practice of Compassion in Supervision in Residential Treatment Programs for Clients with Severe Mental IIIness
}

Katherine Tyson McCrea Professor

Loyola University Chicago, ktyson@luc.edu

Follow this and additional works at: https://ecommons.luc.edu/social_justice

Part of the Social Work Commons

\section{Recommended Citation}

McCrea, Katherine Tyson Professor, "The Practice of Compassion in Supervision in Residential Treatment Programs for Clients with Severe Mental Illness" (2008). Social Justice. 34.

https://ecommons.luc.edu/social_justice/34 for inclusion in Social Justice by an authorized administrator of Loyola eCommons. For more information, please contactecommons@luc.edu. 


\title{
The Practice of Compassion in
}

\section{Supervision in Residential Treatment Programs \\ for Clients with Severe Mental Illnessi}

\author{
Katherine Tyson McCrea, Ph.D., L.C.S.W. \\ Jeffrey J. Bulanda, Ph.D. L.C.S.W.
}

\begin{abstract}
Clinical supervision for residential care staff is essential, and yet has rarely been studied. Drawing from the reflective practice tradition, we interviewed residential care supervisors about their clinical decision-making process, and analyzed the data qualitatively to identify common themes and distill their beliefs and reported practices. We found supervisors prioritized a compassion-based model of supervision characterized by fostering staff self-care, developing staff's empathy and responsiveness to clients, helping staff with disappointments in their relationships with clients, accurately evaluating client progress, preserving safety, and nurturing teamwork. Supervisor's subjective experience of their caregiving of staff could be explained using a second-level analytic concept we termed a caregiving heuristic - one's beliefs, values, and guidelines for action as a caregiver - of which compassion was, for these supervisors, a foundational element. The supervisors envisioned compassion as a central means by which they could prevent compassion fatigue, develop their staff's caregiving heuristics, and improve job satisfaction and quality of client care.
\end{abstract}

Keywords: Compassion, clinical supervision, compassion fatigue, residential care

The Practice of Compassion in Supervising Residential Treatment for Clients with Severe Mental Illness p. 1 of 33 Paper in press in The Clinical Supervisor, 2008. Please do not cite or reproduce without permission. 
"Pools of caring are created at each level and spill over like waterfalls down the organization, finally depositing in streams of care-seekers"

(William Kahn, 2005, p. 45).

\section{Introduction}

\section{Purpose}

On a cold winter night not long ago, staff members in an urban public psychiatric hospital were faced with such crowded conditions that only the most acutely dangerous clients could be admitted. Even more, the weather was life-threateningly frigid, food pantries were closed, and shelters were full. So, when several severely mentally ill and homeless clients came to the intake office, the staff used furniture in the intake rooms to create a temporary residential care community. The creativity and compassion of the staff were responded to in differing ways. The hospital administrators were greatly concerned about the potential legal exposure involved in housing clients in inadequate units. Perhaps mirroring others' attitudes, the staff experienced mixed feelings about their own compassion. But the staff's immediate supervisors fully supported their actions.

The compassion expressed in this incident is typical of many more episodes we encountered when interviewing managers (who generally also function as clinical supervisors) of residential care programs for severely mentally ill clients in a large Midwestern metropolitan area. The managers themselves said that compassion was the most important ingredient for their work and for staff development. The great majority of supervisors agreed with one who strove to create a "respectful environment" in which "people feel cared for and it is cycle which keeps growing." Impressed by the importance of compassion for these managers and also for practitioners, we examined episodes of compassion reported to us and the clinical, empirical, and theoretical literature on the subject. We found that relatively little has been written about the psychological processes involved in compassion, which is striking because it is so important

The Practice of Compassion in Supervising Residential Treatment for Clients with Severe Mental Illness p. 2 of 33 Paper in press in The Clinical Supervisor, 2008. Please do not cite or reproduce without permission. 
for clinical practice. Moreover, since the 1980's (Pines, 1981), burnout and compassion fatigue have been widely recognized as significant hazards for professional caregivers and as potent obstacles to clinical effectiveness (Adams, Boscarino, \& Figley, 2006; Figley, 1995; Koob, 2002). Considerably more theory development and data are needed to better understand compassion and how it can be developed in the various aspects of clinical practice (Falvey 2002), and our study was designed to take a step in that direction.

\section{Methodology}

The sample for this study was systematically selected. Starting within a 20 mile radius of the center of a large Midwestern city, we compiled all 81 residential care programs treating clients suffering from severe mental illness (including those with substance abuse, AIDS, homelessness, or domestic violence). Every program supervisor was contacted and asked if s/he would participate in an hour-long interview about her/his experience providing residential care. A total of 18 supervisors agreed, which comprises the sample for this study. Of the facilities whose supervisors we interviewed, the primary criterion for client admission was an Axis-I diagnosis, most commonly schizophrenia. Some programs treated clients with who also suffered from other severe difficulties including disease (e.g., HIV/AIDS), mild mental retardation, domestic violence, substance abuse and homelessness. Client lengths of stay ranged from 4 months to indefinite. We investigated whether staff-client ratios, policies about lengths of stay, and the clinical focus of the program were related to the supervisors' decisionmaking approaches, but found no consistent patterns emerged.

Interviews were semi-structured, based on an ethnographic interview model. Questions were formulated and revised through research team discussions, with the aim of helping interviewees maximally share their beliefs and practices in making clinical decisions. While there were 15 questions to be asked (see Appendix), the interviewer followed the interviewee's

The Practice of Compassion in Supervising Residential Treatment for Clients with Severe Mental Illness p. 3 of 33 Paper in press in The Clinical Supervisor, 2008. Please do not cite or reproduce without permission. 
pace and train of thought, probing frequently to clarify meanings (Patton, 2002; Spradley, 1979). To begin, interviewers asked managers about the most important characteristics of a good program manager. The intent was to help the managers feel at ease and focus on their strengths, goals, and values. The remaining questions were asked in an order attuned to the supervisors' responses, to maximize a relaxed, reflective atmosphere.

Data were analyzed in three waves. In the first wave we compiled common themes across supervisors that responded to specific questions, such as their beliefs about what constitutes a good supervisor and the challenges they faced. This initial wave resulted in the finding that they regarded compassion as a central personality strength in a good supervisor. The second wave of qualitative analysis was to compile the specific components of supervisors' beliefs about caring for clients and for staff, also examining the relationship between their beliefs and published, formal theories. This second wave resulted in our finding that while supervisors did not prioritize applying formal theories, they did have systematic beliefs, values, and guidelines for action that could be conceptualized as a caregiving heuristic (see McCrea \& Bulanda). The third wave was to examine in detail the supervisors' discussions of compassion and examples of it in their practice. Negative case analysis was used to understand responses that did not fit within the most prevalent themes (Lincoln and Guba, 1985; Patton, 2002). The data were coded by at least two of the researchers and inter-rater reliability (agreements) was $100 \%$. The analysis presented builds on the first two waves of data analysis but focuses primarily on presenting findings from the third wave, in which we delved into the supervisors' experiences of compassion.

The relatively small sample size and qualitative analysis have well-known limitations in terms of applicability; yet these same design elements also allow for more in-depth examination of patterns of meaning within and across subjects, and are optimal for the exploratory nature of

The Practice of Compassion in Supervising Residential Treatment for Clients with Severe Mental Illness p. 4 of 33 Paper in press in The Clinical Supervisor, 2008. Please do not cite or reproduce without permission. 
this study (Lincoln and Guba, 1985; Patton, 2002). So as to not overstep our data, we focused our analysis on findings that held up across almost all supervisors and that also have support from research studies about developing empathy and preventing compassion fatigue via supervision.

\section{The Context of Residential Treatment}

\section{Program Characteristics}

Residential treatment programs for clients with severe mental illness have not been easy to classify: they are not hospitals or health care organizations, do not usually receive direct funding from a government agency, and, if they do, the rules of governance are still in development. Administrative contexts and structures of accountability vary profoundly, as some programs are small and freestanding, while others are offshoots of large institutions such as hospitals. In this state as in many others, the state government has encouraged housing initiatives of various kinds in order to move clients out of state-operated facilities, resulting in a number of small start-up housing programs. Housing programs vary considerably in the staffto-client ratio, lengths of stay, and staff qualifications. In addition, the clients of housing programs tend to have diverse difficulties and capabilities. The very diversity and lack of common classification of housing programs compounds difficulties conducting systematic comparative research across facilities, and makes it more complicated for program supervisors to learn from each others' experiences.

\section{The Supervisors' Perceptions of their Role}

Kadushin and Harkness identified three primary functions of supervision in social work: administrative, educational, and supportive (2002). To understand how they perceived their role in the program, we asked supervisors about their responsibilities, how they evaluated their effectiveness, the challenges they faced, and the qualities of a good program supervisor. Qualitative analysis (Patton, 2002; Spradley 1979) of the supervisors' descriptions yielded an 
expansion of Kadushin and Harness' functions to include eight key responsibilities that they carried out on a regular basis. The great majority of supervisors believed it was most rewarding to foster the individual capabilities of the staff and to help staff help clients develop their autonomy and strengths (by comparison with a goal of 'warehousing'). They accomplished these goals with eight specific responsibilities (numbered below).

The supervisors saw themselves as responsible for educating staff, many of whom did not bring sufficient training to their work to handle the complexity involved (1). They sought to develop cohesive, supportive teams (2), a theme most of them emphasized several times (see also Kahn, 2005, p. 46). They promoted teamwork by being "respectful of staff, being willing to help with day-to-day operations regardless of status" and "doing things 'below you' - [it's] not acceptable to have an 'it's not my job' attitude." They also solicited feedback from staff so as to have a larger pool of ideas. It was also important to set a good example for committed teamwork, such as putting in longer hours so that staff would emulate dedication rather than just 'punching the clocks.' The supervisors also included among their central responsibilities caring for staff's emotional needs (3), and ensuring their safety (4). Supervisors sought to "maintain the values of the program" by upholding program standards and values and leading with honesty and integrity (5). They mentioned the difficult experience of having to enforce rules, and having the courage to handle staff's resulting anger (6). They strove to be organized and multi-task and to complete paperwork reliably (7). Finally, most supervisors saw caring for clients as an important part of their role (8). In sum, a residential care manager needs to be a 'renaissance person' in the sense of combining clinical, organizational, accounting, and supervisory skills, all at the same time. The task is evidently more challenging when one recognizes that the clients served are often periodically out of touch with reality, suicidal, or 
violent towards others, and that at every moment the supervisor carries responsibility for many human lives.

\section{Challenges Confronting the Supervisors}

The supervisors reported six key, recurrent types of challenges:

1. Staff development: The supervisors recognized the limitations in their staff's professional knowledge and the need to provide additional training. In a typical program, the staff with the most interaction with clients were high school or bachelor's level mental health workers. There might be a nurse in a supervisory role (in our sample, all LPNs had to be certified). Nine programs required a B.A. for the case management position, two required state clinical social work licenses, three required "experience," and fourteen preferred experience but did not require it. Training modules are required by this state, and varied a great deal from program to program. A sample program offered training on first aid, human rights, medications, communication training, and abuse and neglect prevention. The overall picture is one in which staff come to a residential care program with minimal education in counseling, and depend almost entirely on their program for training and clinical supervision -- yet these are the staff who are responsible for prolonged daily care of clients who suffer from the most serious mental illness and environmental challenges. Not surprisingly, the supervisors wished they had more support for staff development in a number of areas.

2. Supervisors continuously struggled with a dearth of resources available, especially limited staff and funding. One supervisor found it difficult to obtain winter socks for his residents; another wanted to take residents to a baseball game occasionally. Even so, the great majority of supervisors were undaunted in their advocacy for their often-disenfranchised clients, as illustrated by one supervisor who said that she would "take people even if they are 
not funded and then fight to help them get funded." Other supervisors expressed concerns for the safety of residents due to lack of available safe housing after discharge.

Supervisors expressed concern that shortage of staff compromised quality of care and caused the staff to be isolated and lonely. Those facing a high (1:30) staff-to-client ratio felt that often staff were not able to base their care plans on offering individualized, supportive relationships with the residents. In addition, supervisors wanted to be able to provide higher salaries, training, and on-going educational opportunities, such as tuition reimbursement, for their staff. They feared that they would lose staff, or might only be able to attract individuals who lacked requisite skills if they could not offer competitive compensations. Compounding the problem, many supervisors were facing pressure to cut back on their already severely limited resources.

Despite the lack of resources, the majority of supervisors reported satisfaction with staff turnover rates (every three years on average), and many reported even less frequent changes in staff. For instance, one supervisor said that $35 \%$ of the staff had been employed there for 10 years (since the program opened). As we will see, the supervisors connected employee retention with their own provision of support and compassion for the staff.

3. Eight of the eighteen supervisors reported difficulty in managing administrative issues within the agency that housed the residential care program, which included "navigating bureaucracy" to meet the needs of the program, their agency's inefficient management of program funds, and concern that "deficits in my program need to be understood rather than ignored [by higher level management]."

4. Collaboration with other agencies is an essential aspect of the residential care context, as the programs exist in a complex network of referrals, funding sources, public and private community support services for residents, and discharge options. For 38\% of the supervisors,

The Practice of Compassion in Supervising Residential Treatment for Clients with Severe Mental Illness p. 8 of 33 Paper in press in The Clinical Supervisor, 2008. Please do not cite or reproduce without permission. 
these networks were considerably strained, as they desscribed problems interacting with external departments and agencies, including: "referral sources need to be forthcoming about client problems," "difficulty working collaboratively with staff in other departments and improving the multidisciplinary approach with other departments," and "a divide between residential staff and outside case supervisors and mental health professionals." When residents were ready to be discharged, these supervisors found "difficulty finding permanent housing." The picture that emerges is one in which at least a third of the program supervisors carry out their work uncertain about the stability of external supports for their program.

5. A third of the supervisors also emphasized clinical challenges in working with clients with severe mental illness, including client isolation, aggression, medication noncompliance, poor hygiene, and family underinvolvement. They were concerned about their staff's countertransference reactions, especially those leading to inadequate care, such as wanting to discharge a client prematurely.

6. Finally, supervisors described challenges in fulfilling their own professional interests and goals. Some supervisors felt they did not have enough decision-making capabilities within their program. Others missed their direct work with clients.

\section{Standards Supervisors Used to Evaluate Their Program's Effectiveness}

In addition to the supervisors' subjective definitions of their roles, they also identified standards that they used to evaluate the effectiveness of their program, and thereby, of their own efforts. Eight supervisors used their own judgments about the quality of client care. Five focused on meeting clients' goals. Three focused on providing stable, quality care, saying for examples, "Residents truly feel cared for so they are less likely to do self-destructive things like try to commit suicide," and "To provide consistent quality of care of the residents who are there." The great majority of standards identified by supervisors were defined using

The Practice of Compassion in Supervising Residential Treatment for Clients with Severe Mental Illness p. 9 of 33 Paper in press in The Clinical Supervisor, 2008. Please do not cite or reproduce without permission. 
improvement in client behavior, e.g. stable housing (8) reduced psychiatric hospitalization (7), medication compliance (6), group attendance (5). A couple of supervisors identified organizational endorsements as important, including case managers' judgments about client progress (1) and the state's licensure of the facility (1).

In sum, the supervisors were evaluating their clinical effectiveness based on behavioral changes and positive consumer evaluations by clients who are often regarded as the most difficult to engage and help. One way supervisors in these settings might be able to reduce the risk of compassion fatigue is to add evaluative standards that 1) recognize incremental client and staff progress (Koob, 2002; Walsh, 2002) and 2) reflect the supervisor's behavior, such as providing staff with empathetic formulations of clients' needs and strengths (Figley, 2005).

\section{Foundations for Conceptualizing Compassion in Clinical Supervision}

\section{A Biopsychosocial Foundation for Compassion}

Compassion is derived from the Latin for 'to suffer with' and refers to participation in another's suffering with a desire to alleviate it (Oxford English Dictionary, 1973). Contemporary understandings of compassion derive significantly from multiple philosophical and religious traditions ranging from Buddhism to Christianity, in which compassion is regarded as an essential component of a spiritual attitude (Dalai Lama, 2001; Gilbert, 2005). It is associated with mercy and, in pastoral care, has been conceptualized as the channel by which spiritual healing occurs (McNeill, Morrison \& Nouwen, 1982). Martin Luther King emphasized the social justice component of compassion frequently, as when he said "True compassion is more than flinging a coin to a beggar; it comes to see that an edifice which produces beggars needs restructuring" (cited in Cohen \& Solomon, 1995). Recent findings from neuroscience point towards the human capacity for compassion as grounded in clusters of brain cells in the prefrontal cortex that can resonate with the intentions and feelings of others (Siegel, 1999;

The Practice of Compassion in Supervising Residential Treatment for Clients with Severe Mental Illness p. 10 of 33 Paper in press in The Clinical Supervisor, 2008. Please do not cite or reproduce without permission. 
Tomasello et al., 2005). A 'convergence' of neuroscience findings about 1) 'mirror neurons' that are activated in response to the actions of others, and 2) experimental findings about infants' capacity to imitate and understand the intentions of others, indicate that the human capacity for imitation and for understanding the intentions of others, which is active at 6 months of age and grows more powerful and accurate after that time, is the basis for the human capacity for compassion (Meltzoff and Decety 2003).

A focus on compassion can be understood as a natural outgrowth of the recent emphasis in psychology on studying psychological strengths and virtues as opposed to focusing on psychopathology, which has resulted in the identification of 6 virtues and 24 character strengths that are universal in the sense of transcultural (Seligman, Steen, Park \& Peterson, 2005). Compassion seems to be a natural outgrowth of the virtues of humanity, wisdom, and justice that Seligman et al. have identified (Ibid).

Compassion is based partly on empathy, in that it entails the ability to represent and respond to another person's subjective experience. Many years ago, Kohut (1959) conceptualized empathy as a way of knowing and also as an essential component of the therapeutic action. Also within the psychoanalytic tradition, Roy Shafer (1976) understood empathy as the capacity to have an inner representation of the other by which the therapist could understand and anticipate the client's subjective experiences. Empathy can be developed, as Nerdrum and Roonestad (2003) found when they taught therapists empathy as a process of decentering, in which the therapist focuses on the client's subjective experiences, pace, and needs for care. In his formulation (interpersonal neurobiology), Daniel Siegel coined the term "mindsight" to refer to the ability to understand the subjective experience (feelings, intentions, and thoughts) of another. 
A moment's reflection indicates that within the experience of compassion one can have many foci - e.g., feelings, thoughts, and intentionality. A focus on intentionality - the goals or ideals one wants to bring about -- is in concert with contemporary evidence about the primacy of intentionality in human relating. Before the onset of language, humans experience relationships in terms of their perceptions of their own and others' intentions (Tomasello, Carpenter et al. 2004). One-year-old infants demonstrated the capacity for empathically perceiving others' motives associated with interest and curiosity (Tomasello and Haberl, 2003). This early capacity for perceiving the intentions of others and developing shared meanings of self and others' intentionality is the foundation for intimacy, attachment, and culture (Tomasello et al., 2004). Caregiving is most facilitative of a secure mother-child relationship and of the child's development of self-regulation by focusing on the intentions, or motives, of the child (Oppenheim \& Koren-Karie, 2002; Oppenheim, Goldsmith, \& Koren-Karie, 2004). Recognizing the cared-for person's intentions (what s/he wants to make happen) implicitly respects the other's autonomy and self-determination, and promotes the cared-for person's acquisition of healthy self-efficacy and self-worth (Schore, 1994; Siegel, 1999).

Compassion takes a step beyond empathy in that it includes action to express solidarity with those suffering, efforts to alleviate suffering, and enabling others to feel cared for despite intractable physical suffering and loss, as in the traditional inclusion of compassion in the physician's role (Huggard 2003)), and in Hospice care. Accordingly, compassionate care makes it possible for those experiencing irremediable physical loss to sustain their psychological integrity and, even, psychological development (assuming the physical loss does not cause deterioration of the brain functions critical for psychological functioning).

In sum, the capacities that make up compassion are intrinsic to the functioning of our minds and are activated by the genetic potential of our brains in concert with supportive, 
nurturing human relationships (Gilbert, 2005; Schore, 1994; Siegel, 1999). Being able to experience and act on compassion is a natural potential of complete human nature -- it is part and parcel with the fundamental human motive to be part of a loving family and community.

\section{Developing Compassion through Organizational Leadership}

Several studies describe organizational processes that can develop and promote compassionate care. Meeting regularly to solve problems, share resources, and support each other is a means by which caregiving organization members can develop their self-worth, professional fulfillment, overall happiness, and resilience to compassion fatigue (Kahn, 2005, p. 179). Perceived procedural injustice has been found to have a statistically significant relationship with the onset of psychiatric disorders in female employees, even controlling for baseline mental state, and when supervisors implement procedural and distributive justice in organizations, it mediates the negative stress associated with organizational changes (Kivimäki, Elovainio, Vahtera, Virtanen, \& Stansfeld, 2003). Research findings about the kinds of communities that promote self-worth indicate that when teammates' behavior consistently reflects natural ideals of justice, each individual's sense of justice is strengthened, as well as that of the team as a whole (Colquitt, 2004; Francis \& Barling, 2005). When community leaders provide generously rewarding treatment and fairness towards community members, the selfesteem and sense of empowerment of the members of the community are powerfully strengthened (DeCremer, Van Knippenberg et al. 2005). These findings point to a model of compassion in residential care supervision that includes a focus on justice and promoting teamwork and mutual support.

\section{Compassion and Preventing Harm in the Supervisory Relationship}

Research documents that social workers' supervisors have a powerful impact on the client's care as well as the supervisee. The quality of supervision has been shown to relate directly to client outcomes: Workers' ratings of the quality of supervisor empathy and problem- 
solving correlated with those workers' clients' ratings of the helpfulness of the workers' services, specifically with regard to the clients' general contentment and goal attainment (Harkness, 1995). In addition, when supervision was client-centered (when the supervisor focused on client needs and care), outpatient adult clients reported more satisfaction with the workers' services than if the supervision focused on administrative or organizational concerns (Harkness and Hensley 1991). Strong et al. found that providing consistent supervision in mental health services communicated to staff that they were valued by the agency, promoted job satisfaction, and reduced turnover (2003, p. 196).

Several guidelines have been formulated for supervisory quality in residential care: regularly scheduled meetings with clients, with additional help with crises, and reflective discussion about the supervisee's behavior vis-à-vis the client (Cohen, 1992). Supervision enables counselors to understand what comes from without (i.e., from the clients) and what comes from within (i.e., the counselors' self-perceptions, (Cohen 1992), ensuring their ongoing competent handling of the challenging clinical circumstances that arise in residential care with severely mentally ill clients. Clinical supervision can prevent a dynamic Berke (1999) called "malignant mirroring," in which staff respond to clients' symptomatic behavior with verbal aggression, such as rejection. To effectively help staff manage such countertransference reactions, the supervisor needs to create a tone in the relationship where support and sharing far outweigh negative judgments. In fact, experienced supervisors emphasize the importance of self-disclosure about their own inner struggles in caring for clients as a way to help supervisees feel more comfortable sharing authentically (Walsh, 2002).

Compassion is likely to prevent the supervisor from acts of psychological violence or cruelty that have been identified as the antithesis of compassion (Gilbert, 2005) and that are the dark side of the power of a supervisory relationship (Watkins, 1997). While understanding

The Practice of Compassion in Supervising Residential Treatment for Clients with Severe Mental Illness p. 14 of 33 Paper in press in The Clinical Supervisor, 2008. Please do not cite or reproduce without permission. 
potential harm is not amenable to systematic study for obvious ethical reasons, and we could not find studies of psychological harm in residential care supervision, the possibility this can occur is suggested by studies about harm in psychotherapy (Strupp, Hadley, \& GomesSchwartz, 1977; Tennov, 1975), and harmful group and community processes (Zimbardo, 2007), also often referred to in lay terms as 'cults' (Singer, 2003). Studies of harmful supervision indicate that supervisors can aggravate staff compassion fatigue when they are negligent and withhold support (Greer, 2002), evaluate staff with a negative focus on errors, aggravate their fears of failure (Noelle, 2002) and undermine, rather than bolster, staff's self-efficacy (Koob, 2002).

There are several features of residential care that can potentiate the risk of harm through supervision. Unlike outpatient psychotherapy, which is typically 1-1, with supervision occurring based on the therapist report of interview process within the confidentiality of the supervisory relationship, in residential care many staff and also the supervisor know each client and interact with her/him. This context creates immediate checks on any one staff member's perceptions, checks that can function constructively in enhancing accuracy, but also destructively, if staff members' accurate judgments are undermined.

While we did not hear of examples of psychological harm in the 18 supervisors we interviewed, two brief examples from consultative experience illustrate the sensitivity of a residential treatment community to potential harm when supervision is cruel rather than compassionate. In the first example, a supervisor responded to staff members' discussions of their work in an accusatory, pathology-focused tone, saying for instance, "your problem is that you don't see their pathology," and frequently commented about how onerous it was to help staff "see what is obvious." Consequently, staff felt badly about themselves and found it 
difficult to form and sustain alliances with clients. One began falling asleep while meeting with clients, and another began to "read the riot act" to clients whose symptoms did not improve.

Another feature distinctive to milieu treatment settings is that clients may voice their negativity about a staff member very publicly. While the public context has the advantage of ensuring client complaints about services are heard, it also increases the risk of boundary violations and humiliation for staff members involved in negative interactions. As many researchers have pointed out, humiliation can be psychologically traumatic and toxic (Nathanson, 1992, 1994, 1997; Schore, 1994). In the second example, one program supervisor established a custom of transferring clients from one primary worker to another in the public context of a staff meeting, for reasons that had not been clarified with the staff member. The supervisor also had trouble maintaining the confidentiality of supervisory conferences, making pejorative remarks about one supervisee's work to another supervisee. The staff, unaware of their right to confidentiality in clinical supervision, were very fearful about the humiliation associated with what they saw as public exposures of their failures. They also became more withdrawn from clients and started scapegoating and excluding whichever staff member was currently regarded most unfavorably by the supervisor, undermining their teamwork and aggravating the climate of fear. The harm created by the supervisors in the above examples was so serious that repair of the programs could not begin until the supervisors were terminated.

\section{A Compassion-based Model of Staff Supervision}

\section{The Supervisors' Definitions of Compassion}

As noted above, the supervisors identified compassion as essential in a good program supervisor. As one supervisor eloquently stated, "It is important to understand the stresses of the staff, to be able to put yourself in their shoes, and in the shoes of the resident. Compassion for others and balancing this with making sure the work gets done is what is most important."

The Practice of Compassion in Supervising Residential Treatment for Clients with Severe Mental Illness p. 16 of 33 Paper in press in The Clinical Supervisor, 2008. Please do not cite or reproduce without permission. 
Another supervisor said, "It is vital to be respectful of staff, being willing to help with day-today operations, regardless of status." When asked about the qualities of a good program supervisor, another supervisor said, “Compassion, empathy, boundaries, good listening, working knowledge of diagnoses, ability to communicate on a human level, 'I am on an equal playing ground as the member,' not show superiority but set up boundaries. Sense of fun and humor!" In their view, compassion was typically associated with empathy, teamwork, acting so as to ease the psychological pain of others, using reasonable discussion rather than punishment, and helping others through setting examples and constructive discussion of difficulties.

The supervisors' use of the term compassion resonates with the traditional definitions described previously. Whereas the supervisors regarded compassion as a process that was rewarding and something they aspired to - not as intrinsically burdensome - it has been found to be risky. Figley writes, “The very act of being compassionate extracts a cost under most circumstances. In our effort to view the world from the perspective of the suffering, we suffer." (p. 1434). Figley defined and studied compassion fatigue as identical with Secondary Traumatic Stress Syndrome in the DSM-IV (p. 1435). He distinguished compassion fatigue from countertransference, which occurs via "chronic attachment to the client associated with family of origin relationships" (1435). Compassion fatigue has also been distinguished from burnout, which was defined by Pines and Aronson (as cited in Figley, p. 1435) as "a state of physical, emotional, and mental exhaustion caused by long term involvement in emotionally demanding situations.'" Numerous studies from the United States and Australia document how most counselors are at risk for compassion fatigue and burnout, with ranges from $54.8 \%$ to 76.5 ; studies of mental health workers and nurses document similar incidence (cited in Figley, 1995; see also Adams, Boscarino \& Figley, 2006; Sabo, 2006; Simon, Pryce, Roff \& Klemack, 2005). 
The supervisors said their compassion for staff was a balm to prevent compassion fatigue. Also, their compassion for staff reflected the process they wanted the staff to carry out with the clients, and so the supervisors prioritized fairness, support, and being a good team member. As one supervisor said, she strove to

Create a culture of solving problems together, the nature of the [patients'] disease is isolation and no relationships, this is a chance for people to work together with others and hopefully that will transfer to the outside world (this environment is a microcosm of the world and if a resident can make it there, than he can make it outside of program).

She emphasized that,

Discussions are always understanding and not punitive; when a resident doesn't comply with rules it is a diagnostic indicator [to be treated with empathy].

Another supervisor, who was effective in decreasing turnover and building satisfaction, said his first priority was to teach staff to take care of themselves. He also sought to give staff as much autonomy as possible and provided weekly clinical supervision geared to staff members' level of experience. With this focus, he was effective in doubling the staff's tenure. The central implication of the supervisors' descriptions and other research findings is that the supervisor's compassion for staff enables staff to care for clients compassionately (Kahn, 2005).

\section{Supervisors' Compassion and Staff's Caregiving Heuristics}

Siegel (1999) and attachment researchers (Lieberman et al., 2005; Sroufe et al., 2005) have demonstrated that humans develop frames of reference, grounded in their intentionality and affective experience of caregiving intimacy, that organize the specific meanings that connote caring and being cared-for. In the second wave of data analysis, when we analyzed the residential program supervisor's beliefs about caregiving, we used the term 'caregiving heuristic' to refer to the combination of values, action-oriented guidelines, tacit knowledge, and decision-making processes that comprised the supervisors' processes of clinical decisionmaking (McCrea and Bulanda, under review). In some contexts the term heuristic is used to

The Practice of Compassion in Supervising Residential Treatment for Clients with Severe Mental Illness p. 18 of 33 Paper in press in The Clinical Supervisor, 2008. Please do not cite or reproduce without permission. 
apply to cognitive strategies used to solve problems (Simon, 1966; Tversky \& Kahneman, 1982) or to refer to aspects of scientific theory development and experimentation (Wimsatt, 1986). Our usage of the term heuristic is consistent in that the caregiving heuristic is a higher-order analytic concept (developed in our qualitative analysis [Huberman \& Miles, 1985]) that makes it possible to integrate and comprehend several phenomena reported by supervisors in the first level of data analysis.

First, the supervisors explicitly included compassion as a foundation of their caregiving heuristics. In addition, they reported that staff members had deeply-felt beliefs and practices about what constitutes caregiving, which the supervisors then developed through education and joint case analysis so staff could respond more flexibly and accurately to complex client needs. The staff members at times disagreed with each other passionately about the best way to care for clients, confirming the existence of individually-held beliefs about caregiving practices. What represented optimal care according to one person might not for another. Some staff members were unable to alter their beliefs about caregiving, persisting at times in maintaining practices (and defending them), even though such practices did not represent caregiving from the supervisor's standpoint. And finally, the supervisors experienced the fulfillment of their own caregiving beliefs as critical to their well-being. We will discuss all these examples and the nature and development of caregiving heuristics in the remainder of the paper, but first provide an extended clinical example of how staff's caregiving heuristics were modified by a supervisor's compassion so as to improve the care provided to a challenging client.

Sally had chronic medical problems, including diabetes and heart disease, which were aggravated by self-destructive behaviors, including smoking. She spoke very negatively about clients to others, and fomented conflicts in the treatment community. Samuel (a fellow client) was intimidated by her, picked up on her comments and underscored the damage she was

The Practice of Compassion in Supervising Residential Treatment for Clients with Severe Mental Illness p. 19 of 33 Paper in press in The Clinical Supervisor, 2008. Please do not cite or reproduce without permission. 
doing by mocking whichever client Sally picked on. Sally reacted to disappointments by threatening to 'fire' the staff, and yet if staff followed up on her wishes to leave by proposing alternative placements, turned them down. Every staff member who had worked with Sally described feeling initially rejected; then they became frustrated and started to withdraw from Sally.

After a group meeting with the clinical supervisor, staff began to recognize that her behavior reflected an identification with parents who had been emotionally rejecting, negligent, excessively demanding, and abusive when she could not meet their demands. Given how she had been rejected and abused, Sally experienced her distancing behavior as soothing. Once staff understood this, they no longer took her communications at face value, and responded to her hostility by encouraging her to experience the inclusive community of the residential care program. For instance, rather than looking for alternative placements, they said, "let's talk through what you're unhappy about." When she resisted going to group by saying she was leaving the program, they started saying to her, "okay, but as long as you're here today, you need to go to group today." Sally began to calm down, internalizing the staff's compassion and emotional generosity, and the staff felt competent rather than rebuffed.

The supervisor's compassion consisted of several elements, which the staff members emulated and internalized:

1. Accurately and non-pejoratively understanding the obstacles inside the supervisee that impede developmentally facilitative responses to clients (such as, in the case of Sally, the staff members' feelings of shame and frustration at being rejected);

2. Fostering the supervisee's self-care;

3. Helping the supervisee to understand the subjective experience of the client in a more accurate way (through empathic explanation, as in the case of Sally above);

4. Helping the supervisee to plan actions to provide the caregiving the client needs. (Although often the supervisor's support enables staff to generate caregiving responses, at times the supervisor needs to suggest them, as they may be outside the scope of the caregiving heuristics that the supervisee has available internally; e.g., the supervisor suggested potential staff responses to Sally's rejecting behavior).

The Practice of Compassion in Supervising Residential Treatment for Clients with Severe Mental Illness p. 20 of 33 Paper in press in The Clinical Supervisor, 2008. Please do not cite or reproduce without permission. 
Following are further examples in which supervisors implemented a compassion-focused model of supervision to develop their staff's caregiving heuristics.

\section{Developing Staff's Clinical Understanding of Client Difficulties}

Staff members' caregiving heuristics guide their assessment, interventions, and evaluations of client progress, as seen in the example above. While each staff member has particular goals for his/her clients, for the most part residential care for clients with severe mental illness is not a job where workers see immediate positive outcomes resulting from their work. Indeed, this client population has many features that can potentially be labeled failures -frequent rehospitalizations, relapses into drug abuse or psychosis or violent behavior, exercising poor judgment and going 'awol' from the program, etc. (Walsh 1986). Such client reactions can represent serious disappointments for supervisors and staff, and how supervisors and staff respond to these disappointments is critical for the client's outcome. As Figley points out, compassion fatigue often results when one's 'sense of achievement' is frustrated (1995) because goals set for clients do not match what clients can accomplish. Accordingly, one of the most important ways a clinical supervisor helps staff develop their caregiving heuristics is to help staff conceptualize realistic goals for clients and see client progress that is occurring in even small steps.

An example is the client mentioned above, Samuel, who had responded so destructively to Sally's provocative behavior. Samuel had returned to the program after yet another brief hospitalization for a substance abuse relapse. Staff felt that Samuel had not made good use of the program's aid in the past, and that the relapse and recidivism meant that he was unable to benefit from help. The supervisor guided staff in making a more accurate assessment of the client's subjective experience, helping them to recall that 40-year-old Samuel had had a serious problem with abuse of alcohol and drugs since high school, without any period of abstinence

The Practice of Compassion in Supervising Residential Treatment for Clients with Severe Mental Illness p. 21 of 33 Paper in press in The Clinical Supervisor, 2008. Please do not cite or reproduce without permission. 
outside a residential setting lasting longer than 3 weeks. Until he came to their residential program, he had not been able to sustain any ongoing relationship with any caregiving agency. Over many years he had been permanently estranged from his family of origin, lost several jobs, and was unable to form any permanent relationships. When the supervisor helped staff to more accurately perceive Samuel's history, they also could alter their goals and recognize that Samuel had made significant accomplishments in their program: 1) he had stayed drug-free for 3 months, and 2) when he had the significant loss of being mugged outside his church and started to drink again, he turned for help to the program staff for help rather than persisting with drinking excessively. This revised understanding of Samuel's needs and progress helped staff to appreciate both the client's motivation to benefit from care, and also that the care they had provided was resulting in significant incremental improvements in his self-caretaking functioning.

The supervisor's compassion is also essential in modifying staff caregiving heuristics that may be unrealistically demanding of the staff member. The high stakes of residential care human lives -- considerably magnifies the consequences of staff mistakes. In addition, staff's prolonged involvement in recreational and home-type activities can make the boundaries around their accountability difficult to define. They can feel distraught, guilty, and ashamed if a client in their care is endangered. For instance, Tess went on a pass accompanied by a staff member, Joseph. While in the restroom, she cut her foot and then hid the cut with a sock for hours. She never told Joseph she was bleeding, and when he later learned of it, he was beside himself with self-castigation and worry for her, clearly bringing to his work an unrealistic belief that he should have been able to get clients to tell him about all their struggles. Joseph's supervisor helped him understand that he was not to blame for Tess' self-mutilation, that her difficulty telling him represented Tess' transference and not the staff member's failing, and that

The Practice of Compassion in Supervising Residential Treatment for Clients with Severe Mental Illness p. 22 of 33 Paper in press in The Clinical Supervisor, 2008. Please do not cite or reproduce without permission. 
the caregiving process includes understanding clients' conflicts about confiding in staff.

Moreover, Joseph's supervisor's compassion considerably eased the shame and guilt that he felt (Nathanson, 1997).

\section{Handling Staff Disagreements about Caregiving}

Some supervisors reported that staff may passionately disagree with each other about the best way to take care of clients, which is another indicator that they have strongly-held caregiving heuristics. For example, one supervisor who believed punishments were counterproductive said that some staff complained that "there are no negative consequences." She said, "Staff were frustrated that they could not take more control over the clients' behavior [but because the program's caregiving policies are to be tolerant of clients] Even if a client is drinking in the facility or has a crackpipe, the staff will work with them." She strove to handle such disagreements with a combination of rational discussion and support, facilitating a discussion of differing viewpoints, avoiding scapegoating and power plays within the staff, and helping staff to develop their individual caregiving heuristics so they could accord more closely with the program's caregiving policies.

An example comes from a senior staff member, Leo, who expressed concern to his fellow staff about staff's frequent use of punishment and also the lack of any consistent guidelines, which made the punishments seem arbitrary. Initially defending their caregiving approach, staff became upset and defensive and accused Leo of being so lenient that clients would quit following any program rules and chaos would ensue (suggesting how fulfilling caregiving beliefs feels deeply important to staff and that they associate going against them with detrimental outcomes). The supervisor and Leo encouraged the staff to reflect on their interactions with the clients. Then, staff realized that their punitiveness expressed their anger with clients and that in fact they did not regard taking out anger on clients as part of their

The Practice of Compassion in Supervising Residential Treatment for Clients with Severe Mental Illness p. 23 of 33 Paper in press in The Clinical Supervisor, 2008. Please do not cite or reproduce without permission. 
idealized practices. After discussion, the team decided that in order to prevent taking their anger out on clients, each staff member would get approval from other staff before imposing consequences. This strategy was effective, as the staff started to go to one another when they became upset with the clients and used peer consultation to create optimal responses. As a result, staff's communication about clients' needs improved, punishments decreased, and staff felt empowered about their teamwork. Note that in the above example, staff's values were in conflict with their behavior (punitiveness) and the teamwork process developed their ability to act in accordance with their caregiving values.

\section{Addressing Refractory Performance Problems: "I had to let some people go"}

As noted above, the supervisors emphasized constructive relationships with staff and teamwork as the most important characteristics of a good program supervisor. Only one supervisor referred to punitive or disciplinary action as a cardinal aspect of good management. She commented, "You have to be willing to be the 'bad object' to your staff, " and was struggling in other ways: she was the only supervisor who could not describe any positive clinical outcome, and who felt that the clients in her facility were too dysfunctional for her program. Supervisors concentrating on teamwork and empathizing with their staff were more likely to use strengths-based approaches with their clients and took pride in clinical successes.

In other contexts in the interviews, supervisors described problems with staff that required disciplinary interventions. One stated, "a few years ago the professional environment was too relaxed...I reevaluated this in order to increase professionalism, called people on it, and had to let some people go." Another expressed concerns about her staff's capabilities and suggested that "staff should be required to get psych testing to determine their ability to work with this population." Another supervisor was concerned because she felt "staff can take advantage of the supervisor not being present at all times... They can get away with a lot."

The Practice of Compassion in Supervising Residential Treatment for Clients with Severe Mental Illness p. 24 of 33 Paper in press in The Clinical Supervisor, 2008. Please do not cite or reproduce without permission. 
Evidently, some staff may not be able to sufficiently modify their caregiving heuristics to meet the organization's standard.

Research findings support the supervisors' emphasis on staff development, with discipline secondary. What used to be termed 'employee discipline' is increasingly replaced by a focus on helping staff develop and learn (Lisoski, 2004). Kadushin \& Harkness suggest that

The best approach is one which communicates concern for the supervisee, a willingness to listen to his explanation of what happened, a desire to understand how he sees the situation, and a readiness to help him change. The emphasis is on a change of behavior so as to increase the agency's effectiveness of service rather than on the apprehension and punishment of noncompliance (2004, p.126).

Hopkins and Austin (2004) further challenge the idea that supervisors need to be punitive in order to attain staff cooperation. In their model of non-punitive discipline, the supervisor focuses on the staff member's development and performance in the future, rather than punishment for past violations. The supervisor actively collaborates with the employee in developing an action plan, and takes the role of a coach. This relationship allows for an open dialogue during which the employee can reflectively discuss the infraction and commit to changing behaviors. All of these theorists emphasize the importance of the relationship, empathy, and compassion in providing and soliciting feedback. The authors also agree that there are times when termination is necessary in order to maintain the integrity of the program and quality of care for the clients. However, this is an option only after the failure of the supervisor's assiduous efforts at an ongoing, empathic dialogue with the employee, and efforts at implementing a remedial staff development plan.

\section{Supervisors' Professional Fulfillment}

Since program management in residential care with severely mentally ill clients is such a highly complex and challenging job, it is not surprising that the program supervisors reported mixed feelings about promotion to a supervisory position. On the one hand, they had a greater

The Practice of Compassion in Supervising Residential Treatment for Clients with Severe Mental Illness p. 25 of 33 Paper in press in The Clinical Supervisor, 2008. Please do not cite or reproduce without permission. 
opportunity to implement constructive changes in their programs; on the other hand, they expressed concern that the responsibilities of management can be isolating, and several supervisors missed working with clients. Accordingly, it is important to help supervisors experience fulfillment in this critical role. Kahn uses the concept of a 'preferred self' to describe the inner structure that regulates self-appraisal and thereby job satisfaction. The preferred self consists of ideals towards which supervisors strive in physically, cognitively, and emotionally maintaining a program and caring for their staff (Kahn, 1990), and if the supervisor is able to actualize her/his preferred self via expressing thoughts and feelings, questioning assumptions, and creative innovations, job satisfaction will follow (Kahn, 2005, p. 321). Kahn's 'preferred self' can be seen as an element of a caregiving heuristic that is desirable to support in staff and supervisors.

Various factors determine how much a supervisor can fulfill his/her preferred self. The first condition is psychological meaningfulness, which is "a feeling that one is receiving a return on investments of one's self in a currency of physical, cognitive, or emotional energy" (Kahn, 1990, p. 705). Supervisors who felt constrained by the challenges noted above felt their investment in the program was not sufficiently rewarding. Second, the supervisor needs to experience psychological safety, "a sense of being able to show and employ self without fear of negative consequences to self-image, status, or career" (Kahn, 1990, p. 705). The third condition for expression of one's preferred self is psychological availability. This condition is determined by the supervisor's own capacity to invest physical, cognitive, and emotional energy into his/her job responsibility. Outside life problems and psychological issues, such as insecurity or anxiety, can prevent the expression of one's preferred self (Kahn, 1990). Finding ways to support supervisors' actualizing their preferred selves is an important future goal for research and practice.

The Practice of Compassion in Supervising Residential Treatment for Clients with Severe Mental Illness p. 26 of 33 Paper in press in The Clinical Supervisor, 2008. Please do not cite or reproduce without permission. 


\section{Conclusions}

In residential care settings, clients with severe mental illness commonly bring to their professional caregivers experiences of trauma, injustice, and deprivation that are shocking and often horrifying. In the intimacy that occurs within a residential care setting, the clients experience the deep fears that these painful experiences will be recapitulated once again. It is the residential care staff who provide the clients with the ongoing experience that human connections can be restorative and deeply gratifying, and who help the clients to discover capacities for self-care and closeness that they did not previously know existed in themselves. To accomplish this goal of healing requires sustained outpouring of skilled, consistent care from the staff, with outreach and patience. The staff in turn need to be nurtured and restored, and the supervisors of residential care programs we interviewed underscored the vital importance of their own compassion as the wellspring for their staff's healing partnerships with clients. The supervisors recounted a form of compassionate caregiving for staff unique to the supervisory process, which included establishing relationships of collegiality and teamwork with staff, helping staff with self-care emotionally and in other ways, offering empathetic formulations of clients' difficulties, supporting staff in the face of clients' seeming rejection or lack of progress, helping staff resolve disagreements with each other about caregiving, helping staff develop their professionalism, and preserving emotional and physical safety. Continued appreciation of the value of residential care supervisors' work is needed, as is continued research into the vital role of compassion in clinical supervision and caregiving organizations.

The Practice of Compassion in Supervising Residential Treatment for Clients with Severe Mental Illness p. 27 of 33 Paper in press in The Clinical Supervisor, 2008. Please do not cite or reproduce without permission. 


\section{Appendix: Survey for supervisors of residential care programs}

1. Call Program Director

Hi I'm from XXX. We're conducting a survey on residential care and we're calling to see if you might be interested in helping us with it by participating in a brief in-person interview. It will be anonymous in that we won't identify any of the institutions by name and we'll disguise any anecdotal data so that no one could recognize your institution or who the clients are. Might you have 30-60 minutes when we might meet?

2. If yes: That's terrific. (schedule time) Also, can you answer a few quick questions now? About how many clients are there?

What are the primary diagnoses/problems?

How long do clients stay there?

What is the staff to client ratio?

Are there staff on the premises 24 hours?

Are the clients required to be in treatment?

Is there a locked portion of your program? Are there clients who are not allowed to leave the premises? If yes, how many?

From where do you get your intakes?

What are your primary funding sources?

During interview, the interviewer writes down everything the manager says, also asks, Do you want a copy of this article when it is completed?

1. What do you think are the most important characteristics in being a good program manager?

2. What is staff turnover like?

3. What kind of people do you hire? What kind of experience do you require them to have?

4. What kind of inservice training do you have?

5. Do you have a philosophy or theory that you use in managing your program?

6. What means do you use in the community to help people comply with the rules?

7. How do you set goals with the residents?

8. What means do you use to help clients grow and develop?

9. How do you help the residents reach their goals?

10. Do you use any of the following approaches and how useful are they?

token economy?

patient government?

behavior modification?

dialectical behavioral therapy?

multisystemic (ecological) therapy?

psychodynamic (psychoanalytic or therapeutic community)?

strengths perspective?

functional model (occupational therapy/skills of daily living training?) other?

11. Can you tell me about a case that went really well?

12. Can you tell me about a problem case?

13. How do funding policies affect your program? Are there areas that you would want to change?

14. We don't want to be intrusive but at the same time it would be helpful to get an idea about the outcomes you regard as positive and negative. Do you have a report or article describing the percentages of positive and negative outcomes for your program?

15. Do you feel that your program is effective? Why or why not?

16. What kind of support and supervision would help you improve the program?

The Practice of Compassion in Supervising Residential Treatment for Clients with Severe Mental Illness p. 28 of 33 Paper in press in The Clinical Supervisor, 2008. Please do not cite or reproduce without permission. 


\section{References}

Adams, R. E., J. A. Boscarino, and C. R. Figley (2006). Compassion fatigue and psychological distress among social workers: A validation study. American Journal of Orthopsychiatry 76(1): 103-8. DOI: 10.1037/0002-9432.76.1.103.

Berke, J. H. (1999). Confusions in a therapeutic milieu. In V. L. Schermer, \& M. Pines (Eds.) Group psychotherapy of the psychoses. pp. 388-403. London: Jessica Kingsley Publishers.

Bono, J. E. and T. A. Judge (2003). Self-Concordance at Work: Toward Understanding the Motivational Effects of Transformational Leaders. Academy of Management Journal 46: 554-571.

Bono, J. E. and T. A. Judge (2004). Personality and Transformational and Transactional Leadership: A Meta-Analysis. Journal of Applied Psychology 89(5): 901-910. DOI: 10.1037/0021-9010.89.5.901.

Brotheridge, C. (2003). The Role of Fairness in Mediating the Effects of Voice and Justification on Stress and Other Outcomes in a Climate of Organizational Change. International Journal of Stress Management 10: 253-268. DOI: 10.1037/1072-5245.10.3.253.

Cacioppo, J. T., G. G. Berntson, J. F. Sheridan and M. K. McClintock. (2002). Multilevel integrative analyses of human behavior: Social neuroscience and the complementing nature of social and biological approaches. In J. T. Cacioppo et al. (Eds.). Foundations in Social Neuroscience. pp. 21-46. Cambridge, MA: MIT Press.

Cohen, Jeff and Solomon, Norman. (January 5, 1995). The Martin Luther King You Don't See on TV. Media Beat. Retrieved from http://www.fair.org/index.php?page=2269. August, 2008.

Cohen, Y., and S. Schneider. (1992). The effects of supervision on the self in residential treatment center counselors. Therapeutic Communities: The International Journal for Therapeutic and Supportive Organizations 13(2): 107-115.

Colquitt, J. (2004). Does the justice of the one interact with the justice of the many? Reactions to procedural justice in teams. Journal of Applied Psychology 89: 633-646. DOI: 10.1037/00219010.89.4.633.

Dalai Lama. (2001). An Open Heart: Practicing Compassion in Everyday Life (Ed. by N. Vreeland). New York: Little Brown.

DeCremer, D., B. Van Knippenberg, D. Van Knippenberg, D. Mullenders and F. Stinglhamber. (2005). Rewarding leadership and fair Procedures as determinants of self-esteem. Journal of Applied Psychology 90: 3-12. DOI: 10.1037/0021-9010.90.1.3

Falvey, J. with T. Bray. (2002). Managing clinical supervision: Ethical practice and legal risk management. Pacific Grove, CA.: Brooks/Cole.

Fassinger, R. E. (2005). Paradigms, praxis, problems, and promise: Grounded theory in counseling psychology research. Journal of Counseling Psychology, 52(2), 156-166. DOI: 10.1037/0022-0167.52.2.156

Figley, C.R. (1995). Compassion Fatigue. Florence, KY: Brunner/Mazel.

Gilbert, Paul (Ed.) (2005). Compassion: Conceptualizations, research and use in psychotherapy. London: Routledge.

The Practice of Compassion in Supervising Residential Treatment for Clients with Severe Mental Illness p. 29 of 33 Paper in press in The Clinical Supervisor, 2008. Please do not cite or reproduce without permission. 
Gilbert, Paul. (2005). Compassion and cruelty: A biopsychosocial approach. In Paul Gilbert (Ed.) Compassion: Conceptualizations, research and use in psychotherapy. pp. 9-74. London: Routledge.

Greer, J. (2002). Where to turn for help: Responses to inadequate clinical supervision. The Clinical Supervisor 21: 135-143.

Harkness, D. (1995). The art of helping in supervised practice: Skills, relationships, and outcomes. Clinical Supervisor 13: 63-76. .

Harkness, D. and H. Hensley (1991). Changing the focus of social work supervision: Effects on client satisfaction and generalized contentment. Social Work 36: 506-512. .

Hopkins, K.M. and M.J. Austin. (2004). The changing nature of human services and supervision. In M. J. Austin and K.M. Hopkins (Eds.), Supervision as collaboration in the human services. Thousand Islands, CA: Sage Publications.

Huberman, A.M and M.B. Miles. (1985). Assessing local causality in qualitative research. In D. Berg and K. Smith (Eds.). Exploring clinical methods for social research. Beverly Hills: Sage.

Huggard, P. (2003). Compassion fatigue: How much can I give? Medical Education 37: 163-164. DOI: $10.1046 /$ j.1365-2923.2003.01414.

Judge, T. A. and J. E. Bono, (2005). Core self-evaluations and job and life satisfaction: The Role of self-concordance and goal attainment. Journal of Applied Psychology 90(2): 257-268. DOI: $10.1037 / 0021-9010.90 .2 .257$

Kadushin, A. and D. Harkness. (2002). Supervision in social work, fourth edition. New York: Columbia University Press. .

Kahn, W. A. (1990). Psychological conditions of personal engagement and disengagement at work. Academy of Management Journal 33(4): 692-724.

Kahn, W. (2005). Holding fast: The struggle to create resilient organizations. New York: BrunnerRoutledge.

Kohut, H. (1959). Introspection, empathy, and psychoanalysis: An examination of the relationship between mode of observation and theory. Journal of the American Psychoanalytic Association, 7, 459-483.

Koob, J. (2002). The effects of solution-focused supervision on the perceived self-efficacy of therapists in training. The Clinical Supervisor 21: 161-183.

Lieberman, A.F., E. Padron, P. Van Horn, and W. Harris. (2005). Angels in the nursery: The intergenerational transmission of benevolent parental influences. Infant Mental Health Journal, 26, 504-520. DOI: 10.1002/imhj.20071.

Lisoski, E. (2004). Discipline is for children. Supervision 65: 16-18.

Lincoln, Y. S. and E. G. Guba (1985). Naturalistic inquiry. Newbury Park: Sage.

McCrea, Katherine Tyson and Bulanda, Jeffrey J. (paper under review). Caregiving Heuristics: Valuable Practitioner Knowledge in the Context of Managing Residential Care.

McNeill, D. P., Morrison, D. A. and Nouwen, H. (1982). Compassion: A Reflection on the Christian Life. New York: Doubleday Image Books.

The Practice of Compassion in Supervising Residential Treatment for Clients with Severe Mental Illness p. 30 of 33 Paper in press in The Clinical Supervisor, 2008. Please do not cite or reproduce without permission. 
Meltzoff, A. N. and J. Decety (2003). What imitation tells us about social cognition: A rapprochement between developmental psychology and cognitive neuroscience. Phil. Trans. Royal Society of London B 358: 491-500.

Millard, D. W. (1992). Educated intuition II: A descriptive study of external staff consultancy. Therapeutic Communities: The International Journal for Therapeutic and Supportive Organizations 13(2): 93-106.

Munson, C. (2002). Handbook of Clinical Social Work Supervision. New York: Haworth Social Work Practice Press.

Nathanson, D. L. (1994). Shame, compassion, and the 'borderline' personality. Psychiatric Clinics of North America 17(4): 785-810.

Nathanson, D. L. (1997). From empathy to community. The Annual of Psychoanalysis 25: 125-143.

Nerdrum, P. and M. H. Roonestad (2003). Changes in therapists' conceptualization and practice of therapy following empathy training The Clinical Supervisor 22(2): 37-61. DOI: $10.1300 / J 001 v 22$ n02_04.

Noelle, M. (2002). Self-report in supervision: Positive and negative slants. The Clinical Supervisor 21(1): 125-134.

McNeill, D. Morrison, D., and Nouwen, H. (1982). Compassion: A reflection on the Christian life. New York: Image Doubleday Books.

Oppenheim, D., and Koren-Karie, N. (2002). Mothers' insightfulness regarding their children's inner worlds: The capacity underlying secure child-mother relationships. Infant Mental Health Journal, 23, 593-605. DOI: 10.1002/imhj.10035.

Oppenheim, D., Goldsmith, D., \& Koren-Karie, N. (2004). Maternal insightfulness and preschoolers' emotion and behavior problems: Reciprocal influences in a therapeutic preschool program. Infant Mental Health Journal, 25, 352-367. DOI: 10.1002/imhj.20010.

Oxford English Dictionary. (1973). New York: Oxford University Press.

Patton, M. (2002). Qualitative evaluation and research methods, Third edition. Newbury Park, CA.: Sage.

Pines, A. (1981). Burnout: From tedium to personal growth. New York: Free Press. .

Sabo, B. M. (2006). Compassion fatigue and nursing work: Can we accurately capture the consequences of caring work? International Journal of Nursing Practice 12(3): 136-42. DOI: $10.1111 / \mathrm{j} .1440-172 X .2006 .00562$.

Schore, A. N. (1994). Affect regulation and the origin of the self: The neurobiology of emotional development. Hillsdale, NJ: Lawrence Erlbaum Associates.

Seligman, Martin, Steen, Tracy, Park, Nansook, and Peterson, Christopher. (2005). Positive psychology progress. American Psychologist, 60, 410-421.

Singer, M. T. (2003). Cults in our midst: The continuing fight against their hidden menace. San Francisco, Jossey-Bass.

Siegel, D. (1999). The developing mind: How relationships and the brain interact to shape who we are. New York: Guilford.

The Practice of Compassion in Supervising Residential Treatment for Clients with Severe Mental Illness p. 31 of 33 Paper in press in The Clinical Supervisor, 2008. Please do not cite or reproduce without permission. 
Simon, C. E., J. G. Pryce, L.L. Roff, and D. Klemmack (2005). Secondary traumatic stress and oncology social work: Protecting compassion from fatigue and compromising the worker's worldview. Journal of Psychosocial Oncology 23(4): 1-14. DOI: 10.1300/J077v23n04_01.

Simon, H. (1966). Thinking by computers. Mind and cosmos: Essays in contemporary science and philosophy. R. Colodny. Pittsburgh: University of Pittsburgh Press.

Spradley, J. P. (1979). The ethnographic interview. New York: Holt, Rinehart and Winston.

Sroufe, L. Alan, E. Carlson, W. A. Collins, and B. Egeland. (Eds.). (2005). The development of the person: The Minnesota study of risk and adaptation from birth to adulthood. Guilford Press: New York.

Strong, J., D. Kavanagh, J. Wilson, S. Spence, L. Worrall, N. Crow. (2003). Supervision practice for allied health professionals within a large mental health service: Exploring the phenomenon. The Clinical Supervisor 22(1): 191-210. DOI: 10.1300/J001v22no01_13.

Strupp, H. H., S. W. Hadley, and Gomes-Schwartz, Beverly. (1977). Psychotherapy for better or worse. New York: Jason Aronson.

Tennov, D. (1975). Psychotherapy: The hazardous cure. New York: Abelard-Schuman.

Tomasello, M. and K. Haberl. (2003). Understanding attention: 12- and 18-month-olds know what is new for other persons. Developmental Psychology 39 (5): 906-912. DOI: 10.1037/0012-1649.39.5.906

Tomasello, M., M. Carpenter, J. Call, T. Behne, and H. Moll. (2005). Understanding and sharing intentions: The origins of cultural cognition. Behavioral and Brain Sciences, 28(5): 675-691.

Tversky, A. and D. Kahneman (1982). Judgment under uncertainty: Heuristics and biases. New York: Cambridge.

Walsh, J. (2002). Supervising the countertransference reactions of case managers. The Clinical Supervisor 21(2): 129-144.

Walsh, S. F. (1986). Characteristics of failures in an emergency residential alternative to psychiatric hospitalization. Social Work in Health Care 11: 53-64. .

Watkins, C.E. (1997). The ineffective psychotherapy supervisor: Some reflections about bad behaviors, poor process, and offensive outcomes. The Clinical Supervisor, 16,163-180.

Wimsatt, W. C. (1986). Heuristics and the study of human behavior. In D. W. Fiske and R. A. Shweder (Eds.). Metatheory in social science: Pluralisms and subjectivities. pp. 293-314. Chicago: University of Chicago Press.

Zimbardo, P. G. (2007). The Lucifer effect: Understanding how good people turn evil. New York, Random House.

The Practice of Compassion in Supervising Residential Treatment for Clients with Severe Mental Illness p. 32 of 33 Paper in press in The Clinical Supervisor, 2008. Please do not cite or reproduce without permission. 


\section{Endnotes}

i We would like to thank Emily Carroll, L.C.S.W., Carrie Shonk, M.S.W., Deborah Major, Ph.D., L.C.S.W., the anonymous reviewers of this manuscript, and the program supervisors for their assistance and contributions. Katherine Tyson McCrea, Ph.D., L.C.S.W. is a Professor at Loyola University of Chicago, School of Social Work, and thanks the Loyola University Faculty Development Program for leave time to support this research. Her mailing address: 820 N. Michigan Avenue, Chicago, Illinois 60611.

Ktyson@luc.edu. Jeffrey J. Bulanda, Ph.D., L.C.S.W. is a School Social Worker, Proviso Area for Exceptional Children. His mailing address is 3825 N. Pine Grove Apt. 410, Chicago, Illinois, 60613.

The Practice of Compassion in Supervising Residential Treatment for Clients with Severe Mental Illness p. 33 of 33 Paper in press in The Clinical Supervisor, 2008. Please do not cite or reproduce without permission. 